\title{
GEOPOLITIČNI POLOŽAJ TER TEORETSKI IN METODOLOŠKI POIZKUS OPREDELITVE TIPOV OBMEJNIH OBMOČIJ NA PRIMERU SLOVENIJE
}

\author{
Vladimir Klemenčič*
}

Izvleček

UDK 911.3(497.12-04)

$V$ članku je prikazana problematika obmejnih območij s posebnim ozirom na njihov regionalni razvoj ter opredelitev tipov obmejnih območij v Sloveniji.

Ključne besede: Meje, obmejna območja, demografska območja, Slovenija

Abstract

UDC 911.3(497.12-04)

A GEOPOLITICAL DISCOURSE ON THE LOCATION OF SLOVENIA AND AN ATTEMPT TOWARDS A SOCIGEOGRAPHIC TIPOLOGY OF SLOVENIAN BORDER REGIONS

The paper discusses problems of major border areas with regard to their regional development and the differentiated border region types of Slovenia.

Key words: Borders, Border Regions, Demographic Characteristics, Slovenia

V novejšem razdobju meja, ki se vse bolj uveljavlja kot dejavnik regionalnega razvoja, ne opravlja več funkcije delitve, temveč vse bolj povezovanja med posameznimi državami. Vpliv meje ter stopnja njene odprtosti oziroma zaprtosti pogojujeta tak regionalni razvoj obmejnih območij in oblikovanje specifičnih regionalnih struktur, ki so rezultat stopnje povezanosti in soodvisnosti regionalnega razvoja obmejnih območij od njihovega prekomejnega povezovanja na političnem, gospodarskem in socialnem področju.

Slovenski geografi lahko mirno trdimo, da smo učinke meje pri interpretaciji regionalnega razvoja in razvoja prostorskih struktur zaznali že zelo zgodaj; lahko rečemo, da celo med prvimi v Evropi. Zato se lahko prištevamo med nosilce proučevanja funkcije političnih meja, oblikovanja obmejnih območij ter še posebej funkcije obmejnih, narodnostno mešanih območij, kjer,zaradi obvladovanja jezika in kulture narodov dveh sosednjih držav, stopajo še posebej v ospredje narodne manjšine kot nosilci prekomejnega sodelovanja in povezovanja. Tako so zlasti ob slovensko-italijanski meji manjšine že presegle zgolj funkcijo prekomejnega povezovanja med Italijo in Slovenijo in že pridobivajo na pomenu $\mathrm{v}$ funkciji transkontinentalnega povezovanja med evropskimi državami. Številne razprave, ki so jih od konca sedemdetih let naprej pripravili Klemenčič, Jeršič, Piry, Bufon, Zupančič, Belec in nekateri drugi avtorji, ter njihova primerjava $\mathrm{z}$ rezultati raziskav, publiciranih $\mathrm{v}$ tujem znanstvenem tisku kažejo, da je Slovenija kot celota ena sama obmejna regija z različnimi

* Dr., prof., Oddelek za geografijo, Filozofska fakulteta,Univerza v Ljubljani, 61000Ljubljana, Aškerčeva 2, SLO. 
tipi obmejnih območij glede na oblike, kakor tudi glede na intenzivnost prekomejnega povezovanja in s tem povezanih različnih tipov prostorskih struktur.

Ta razvoj prostorskih struktur in tipov obmejnih območij ter z njimi povezani prostorski problemi so tako v Sloveniji kakor tudi drugod po svetu odvisni v glavnem od treh dejavnikov: - reliefne izoblikovanosti meje, ki loči obmejna območja dveh sosednjih držav,

- gospodarske razvitosti in prekomejnega regionalnega povezovanja,

- politične povezanosti dveh sosednjih držav.

Pri poizkusu klasifikacije obmejnih območij v Sloveniji prav gotovo ne moremo prezreti tudi časovne komponente oblikovanja meja, saj sta današnja slovensko-avstrijska in slovensko-madžarska meja nastali že po prvi, slovensko-italijanska po drugi svetovni vojni, slovensko-hrvaška meja pa šele po letu 1991.

Pri prekomejnem povezovanju obmejnih območij in $\mathrm{s}$ tem $\mathrm{v}$ zvezi tudi pri oblikovanju posameznih tipov obmejnih območij prav gotovo ne moremo prezreti reliefne izoblikovanosti na območjih Julijskih Alp, Karavank in Kobanskega, kjer ta naravna pregrada ovira intenzivno prekomejno povezovanje preko sicer že tri desetletja odprtih meja. Na ostalih območjih, ki so reliefno ugodnejša za prekomejno povezovanje (Goriška Brda, Spodnja Vipavska dolina ter Tržaški kras ob slovensko-italijanski in zahodno Goričko ob slovenskoavstrijski meji), so bile v zadnjih treh desetletjih prednosti odprte meje v regionalnem razvoju zelo dobro izkoriščene. Kljub temu pa se je na teh območjih uveljavila odprta meja v funkciji regionalnega razvoja zopet drugače ob slovensko-italijanski meji med Gorico in Koprom, kot na terciarnem gričevju med Radgono in tromejo pri Trtkovi ob slovensko-avstrijski meji.

Kljub naravno ugodnim pogojem za povezovanje in kljub postopnemu odpiranju meje v zadnjem obdobju ter intenzivnejšemu povezovanju z Madžarsko po letu 1990, pa v regionalni strukturi na obmejnih območjih ob slovensko-madžarski meji še vedno čutimo sledove njene dolgotrajne zaprtosti, ki se kažejo v obliki demografske ogroženosti na skoraj celotnem obmejnem območju. Te nerazvitosti pa ne moremo pripisati zgolj političnim dejavnikom dolgotrajne zaprtosti meje, temveč tudi historično pogojeni prifernosti in oddaljenosti od večjih centralnih krajev na eni ali drugi strani meje. Zaradi tega sta obmejni območji z obeh strani meje ostali, kljub industrializaciji obeh držav, $v$ veliki meri periferni in gospodarsko nerazviti.

Medtem, ko lahko na mejah in v obmejnih območjih Slovenije $\mathrm{z}$ Italijo, Avstrijo in Madžarsko $\mathrm{v}$ regionalni strukturi ugotavljamo funkcijo in učinke meje $\mathrm{v}$ obsežnih, diferencirano prostorskih procesih ter prostorskih strukturah, pa ob novonastali slovenskohrvaški meji lahko zasledimo znake obmejnega značaja regije le neposredno z mejnimi prehodi ter inštitucijami in zgradbami, ki so povezane le $\mathrm{z}$ dejavnostjo policije ali carine. Priče smo tudi vrsti pojavov, ki ovirajo regionalni razvoj, kot je nejasno začrtana mejna črta ali pa problemi, ki so se odprli zaradi pretrganja komunikacij med prebivalstvom obmejnih krajev (zlasti na agrarnih področjih), problemi prekomejnega zaposlovanja dnevnih 
migrantov, pa tudi problemi zadovoljevanja življenjskih potreb $\mathrm{v}$ centralnih krajih, ki so ostali na drugi strani meje.

V prekomejni povezanosti in soodvisnosti regionalnega razvoja obmejnih območij Slovenije z obmejnimi območji sosednjih držav so zelo velike razlike. Tako lahko govorimo na primer o zelo visoki stopnji soodvisnosti s prekomejno povezanostjo na urbaniziranih obmejnih območjih med Novo Gorico, Sežano in Koprom na slovenski ter Trstom in Gorico na italijanski strani. Na teh naštetih območjih so vezi in soodvisnost življenja, gospodarstva, kulturnega življenja in sredstev javnega obveščanja dosegli že tako stopnjo medsebojne povezanosti, da lahko govorimo o tipu obmejne regije, kjer se že javljajo elementi evropeizacije in s tem tudi elementi oblikovanja "Evroregije" s popolno prevlado terciarizacije in postindustrijske družbe.

Tab. 1: Število in tipi mejnih prehodov v Republiki Sloveniji Zahl und Typen der Grenzuebergaenge im der R. Slowenien

\begin{tabular}{l|r|r|r|r|r|r|r}
\hline & $\begin{array}{r}\text { medna- } \\
\text { rodni }\end{array}$ & $\begin{array}{r}\text { meddrž- } \\
\text { avni }\end{array}$ & $\begin{array}{r}\text { obmej- } \\
\text { ni }\end{array}$ & $\begin{array}{r}\text { kmetij- } \\
\text { ski }\end{array}$ & $\begin{array}{r}\text { pla- } \\
\text { ninski }\end{array}$ & $\begin{array}{r}\text { skupaj } \\
\text { štev. }\end{array}$ & delež \\
\hline $\begin{array}{l}\text { slovensko- } \\
\text { italijanska } \\
\text { meja }\end{array}$ & 13 & - & 24 & 14 & 2 & 53 & $42,7 \%$ \\
\hline $\begin{array}{l}\text { slovensko- } \\
\text { avstrijska } \\
\text { meja }\end{array}$ & 11 & 3 & 19 & - & 8 & 41 & $33,1 \%$ \\
\hline $\begin{array}{l}\text { slovensko- } \\
\text { madžarska } \\
\text { meja }\end{array}$ & 2 & - & 2 & - & - & 4 & $3,2 \%$ \\
\hline $\begin{array}{l}\text { slovensko- } \\
\text { hrvaška } \\
\text { meja }\end{array}$ & 19 & 2 & 5 & - & - & 26 & $21,0 \%$ \\
\hline $\begin{array}{l}\text { SKUPAJ } \\
\text { ševilo } \\
\text { delež v \% }\end{array}$ & 36,3 & 4,0 & 40,3 & 11,3 & 8,1 & 124 & $100,0 \%$ \\
\hline
\end{tabular}


Slika 1: Tipi demografskih območij R Slovenije

Die socialgeographische Gliederung Sloweniens

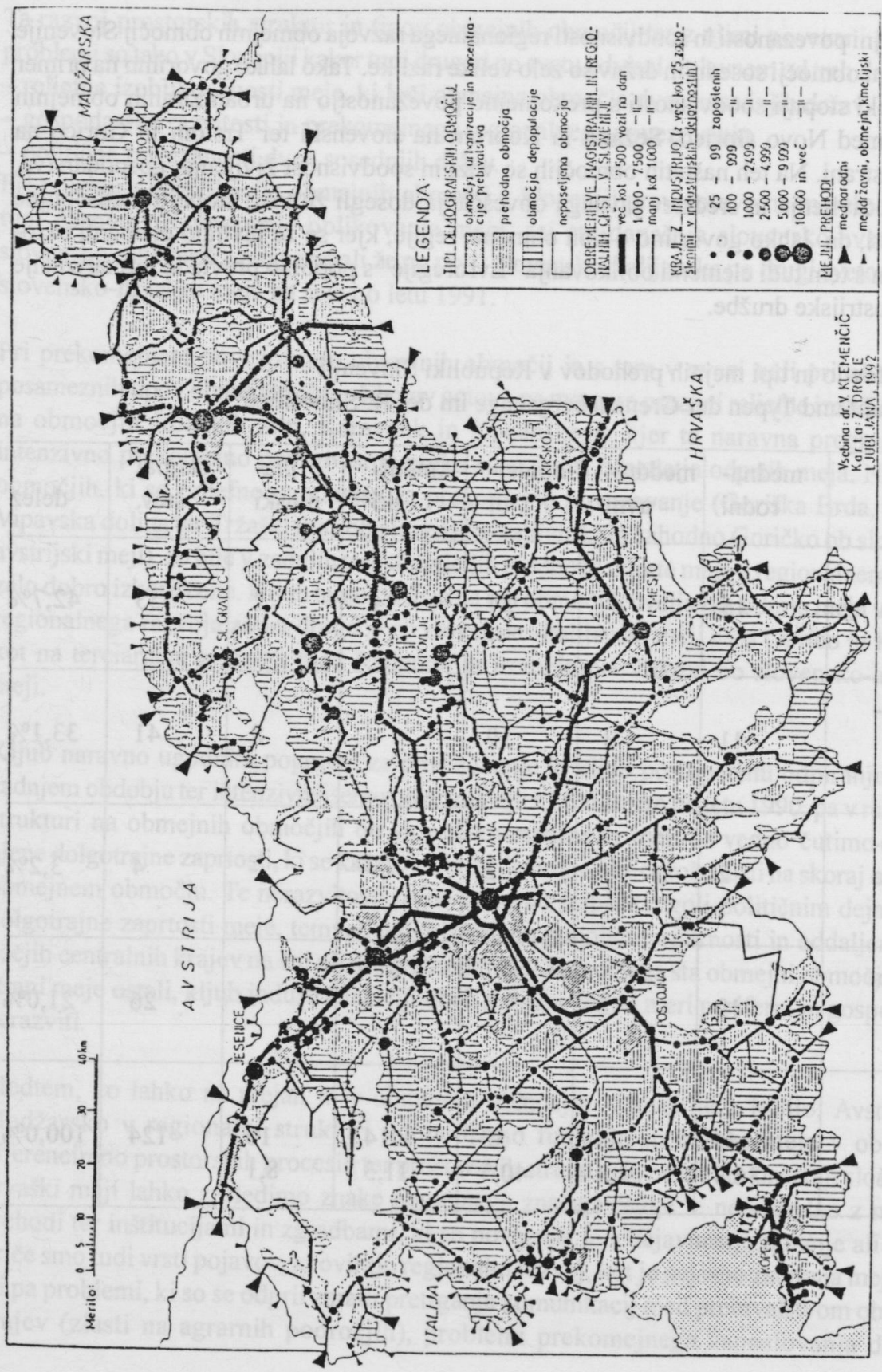


Tab. 2: Obmejne katastrske občine po tipih demografskih območij leta 1991 Grenzkatastralgemeinden nach demographischen Regionen 1991

\begin{tabular}{|c|c|c|c|c|c|c|c|c|}
\hline & & I.kat. & II.kat. & III.kat. & IV.kat. & V.kat. & VI.kat. & \\
\hline $\begin{array}{l}\text { SLO-I } \\
\text { meja }\end{array}$ & $\begin{array}{r}\text { štev. } \\
\%\end{array}$ & $\begin{array}{r}10 \\
15,9\end{array}$ & $\begin{array}{r}7 \\
11,1\end{array}$ & - & $\begin{array}{r}13 \\
20,6\end{array}$ & $\begin{array}{r}5 \\
7,9\end{array}$ & $\begin{array}{r}28 \\
44,5\end{array}$ & $\begin{array}{r}63 \\
100,0\end{array}$ \\
\hline $\begin{array}{l}\text { SLO-A } \\
\text { meja }\end{array}$ & $\begin{array}{r}\text { štev. } \\
\%\end{array}$ & $\begin{array}{r}11 \\
12,5\end{array}$ & $\begin{array}{r}12 \\
13,6\end{array}$ & $\begin{array}{r}3 \\
3,4\end{array}$ & $\begin{array}{r}17 \\
19,3\end{array}$ & $\begin{array}{r}9 \\
10,2\end{array}$ & $\begin{array}{l}36 \\
41\end{array}$ & $\begin{array}{r}88 \\
100,0\end{array}$ \\
\hline $\begin{array}{l}\text { SLO-H } \\
\text { meja }\end{array}$ & $\begin{array}{r}\text { štev. } \\
\%\end{array}$ & $\begin{array}{r}1 \\
4,3\end{array}$ & - & - & $\begin{array}{r}1 \\
4,3\end{array}$ & $\begin{array}{r}1 \\
4,3\end{array}$ & $\begin{array}{r}20 \\
87,1\end{array}$ & $\begin{array}{r}23 \\
100,0\end{array}$ \\
\hline $\begin{array}{l}\text { SLO-CR } \\
\text { meja }\end{array}$ & $\begin{array}{r}\text { Oštev. } \\
\%\end{array}$ & $\begin{array}{r}7 \\
4,3\end{array}$ & $\begin{array}{r}10 \\
6,2\end{array}$ & $\begin{array}{r}5 \\
3,1\end{array}$ & $\begin{array}{c}17 \\
10,\end{array}$ & $\begin{array}{r}27 \\
16,7\end{array}$ & $\begin{array}{r}96 \\
59,2\end{array}$ & $\begin{array}{r}162 \\
100,0\end{array}$ \\
\hline KUPAJ & $\begin{array}{r}\text { štev. } \\
\%\end{array}$ & $\begin{array}{r}29 \\
8,6\end{array}$ & $\begin{array}{r}29 \\
8,6\end{array}$ & $\begin{array}{r}8 \\
2,4\end{array}$ & $\begin{array}{r}48 \\
14,3\end{array}$ & $\begin{array}{r}42 \\
12,5\end{array}$ & $\begin{array}{r}180 \\
53,6\end{array}$ & $\begin{array}{r}336 \\
100,0\end{array}$ \\
\hline
\end{tabular}

Opomba:

I.KAT. - območja trajne koncentracije prebivalstva

II.KAT. - območja novejše koncentracije prebivalstva

III.KAT.- območja starejše koncentracije - število prebivalstva v zadnjem desetletju rahlo nazaduje

IV.KAT.- nekdanja območja praznenja - število prebivalstalstva v zadnjem desetletju rahlo narašča

V.KAT. - novejša območja praznenja prebivalstva

VI.KAT.-obmox̌ja trajnega praznenja prebivalstva

$\mathrm{Na}$ drugi strani pa lahko govorimo o popolnoma drugačnem tipu obmejnih območij ob slovensko-hrvaški in slovensko-madžarski meji, kjer je prebivalstvu otežkočena prekomejna komunikacija. Tudi pravega koncepta, ki bi odgovarjal potrebam prebivalstva in gospodarstva teh obmejnih območij, skoraj ni zaslediti ali pa je šele $v$ zametkih. Ta tip nam bo prav gotovo na osnovi terenskih raziskav prikazan v Belčevem referatu.

Obmejno območje evroregionalnega značaja med Gorico in Koprom pa ne temelji zgolj na povezavi dveh urbaniziranih območij v Sloveniji in Italiji. Temu prostoru daje poseben pomen tudi funkcija prehoda pomembne evropske prometno-gospodarske osi, ki se iz jugozahodne Evrope razteza preko severne Italije in se ravno med Koprom in Novo Gorico oblikuje naprej skozi Slovenijo proti Madžarski, Ukrajini in Rusiji. Pomembnost in specifičnost tega območja povečujeta tudi severnojadranski pristanišči Trst in Koper, od koder se odvija promet $v$ širok prostor Srednje Evrope. 


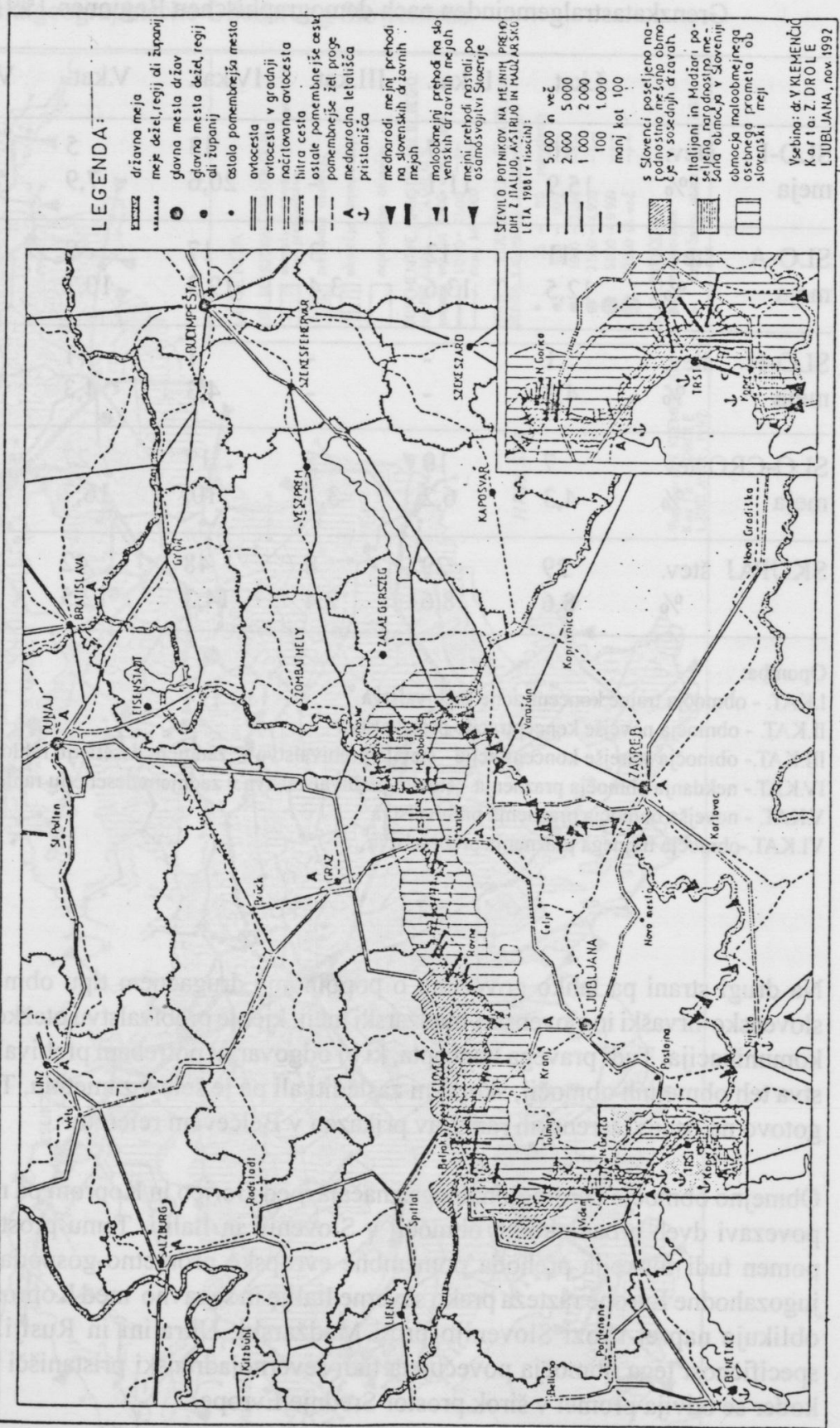


Geopolitični položaj ter teoretski...

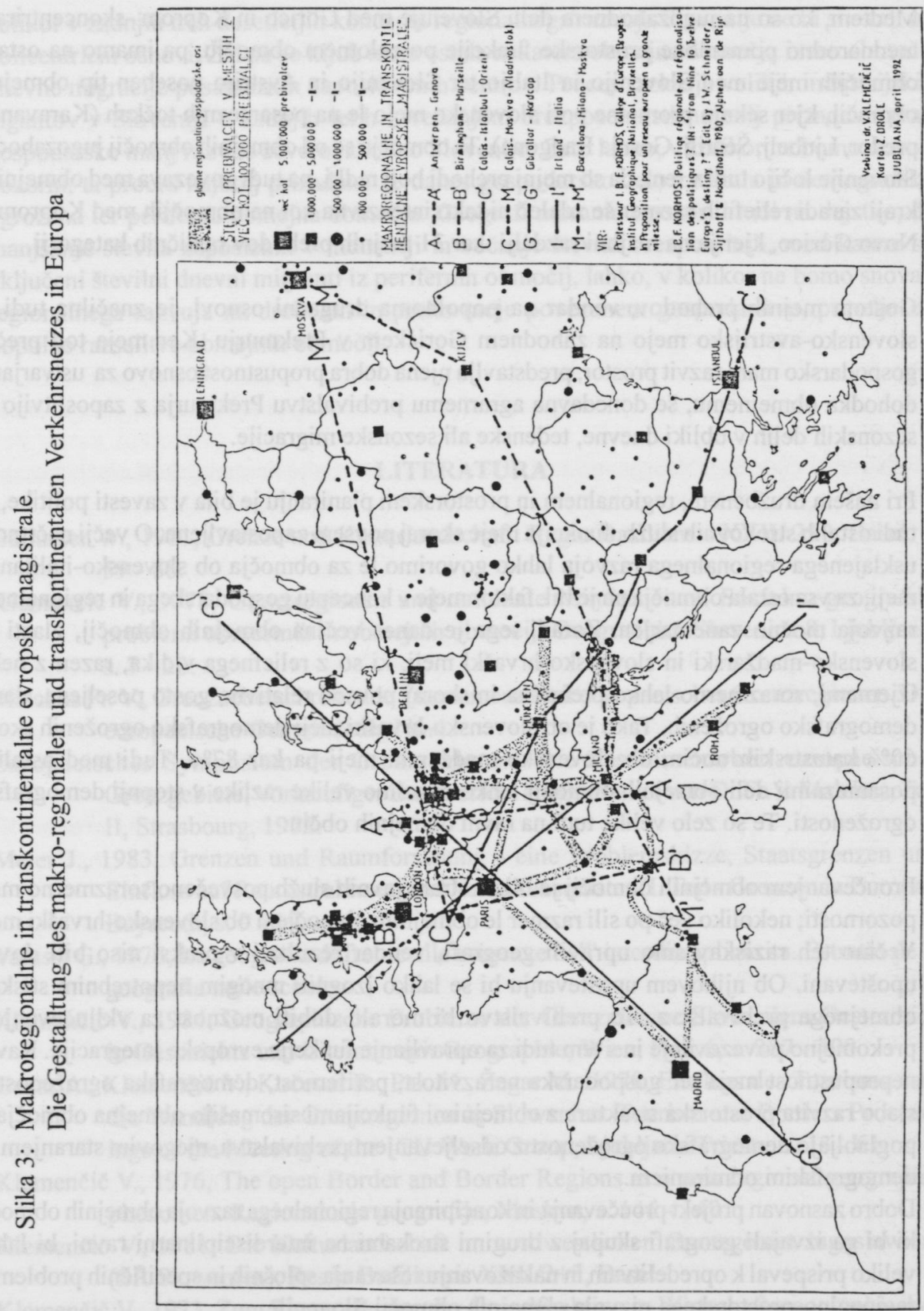


Medtem, ko so na jugozahodnem delu Slovenije med Gorico in Koprom skoncentrirane mednarodno pomembne prostorske funkcije po celotnem območju, pa imamo na ostalih območjih meje med Slovenijo in Italijo ter Slovenijo in Avstrijo poseben tip obmejnih območij, kjer sekajo prometne poti slovensko mejo le na posameznih točkah (Karavanški predor, Ljubelj, Šentilj, Gornja Radgona). Ta območja se od obmejnih območij jugozahodne Slovenije ločijo tudi v tem, da so mejni prehodi bolj redki, pa tudi povezava med obmejnimi kraji zaradi reliefnih razmer še zdaleč ni tako intenzivna kot na območjih med Koprom in Novo Gorico, kjer je na majhni razdalji kar 31 mejnih prehodov različnih kategorij.

Gostota mejnih prehodov, vendar na popolnoma drugačni osnovi, je značilna tudi za slovensko-avstrijsko mejo na zahodnem Goričkem v Prekmurju. Ker meja tod prečka gospodarsko manj razvit prostor, predstavlja njena dobra propustnost osnovo za ustvarjanje dohodka obmejnemu, še donedavna agrarnemu prebivalstvu Prekmurja z zaposlitvijo na sezonskih delih $\mathrm{v}$ obliki dnevne, tedenske ali sezonske migracije.

Pri našem družbenem, regionalnem in prostorskem planiranju je bila $v$ zavesti politike, pa tudi ostalih strokovnih služb, funkcija meje skoraj povsem zapostavljena. O večji načrtnosti usklajenega regionalnega razvoja lahko govorimo le za območja ob slovensko-italijanski meji, za vsa ostala območja pa je bil faktor meje v konceptu gospodarskega in regionalnega razvoja močno zanemarjen. Zaradi tega je danes večina obmejnih območij, zlasti ob slovensko-madžarski in slovensko-hrvaški meji, ki so z reliefnega vidika, razen z nekaj izjemami, sorazmerno lahko prehodna in skoraj povsod relativno gosto poseljena, danes demografsko ogroženih. Tako je ob slovensko-hrvaški meji demografsko ogroženih skoraj $60 \%$ katastrskih občin, ob slovensko-madžarski meji pa kar $87 \%$. Tudi med ostalimi posameznimi deli obmejnih območij lahko opazimo velike razlike $v$ stopnji demografske ogroženosti. Te so zelo velike tudi na ravni obmejnih občin.

Proučevanjem obmejnih območij je bilo s strani javnih služb posvečeno sorazmerno malo pozornosti; nekoliko več po sili razmer le obmejnim območjem ob slovensko-hrvaški meji. Večino teh raziskav smo opravili geografi, vendar rezultati v praksi niso bili dovolj upoštevani. Ob njihovem upoštevanju bi se lahko izognili mnogim nepotrebnim stiskam obmejnega prebivalstva. To prebivalstvo bi moralo dobiti možnost za vključevanje v prekomejno povezovanje in s tem tudi za opravljanje funkcije evropske integracije. Ravno nepropustnost meja ter gospodarska nerazvitost, perifernost, demografska ogroženost in slabo razvita prostorska struktura z obmejnimi funkcijami siromašijo obmejna območja in poglabljajo demografsko ogroženost $\mathrm{z}$ odseljevanjem prebivalstva, njegovim staranjem ali demografskim odmiranjem.

Dobro zasnovan projekt proučevanja in koncipiranja regionalnega razvoja obmejnih območij, ki bi ga izvajali geografi skupaj z drugimi strokami na interdisciplinarni ravni, bi lahko veliko prispeval k opredelitvam in nakazovanju reševanja splošnih in specifičnih problemov regionalno-prostorskega razvoja obmejnih območij Slovenije.

Prav gotovo pa bi lahko bili problemi perifernih obmejnih območij danes še bolj akutni, v 
Geopolitični položaj ter teoretski...

kolikor $\mathrm{v}$ zadnjih treh desetletjih koncepta regionalnega razvoja Slovenije ne bi snovali na policentrični osnovi. Žal pa so kljub temu ostala nekatera obmejna območja izven območij dnevne migracije posameznih zaposlitvenih centrov. Proces razkroja velikih industrijskih gigantov $\mathrm{v}$ Sloveniji $\mathrm{v}$ zadnjih letih $\mathrm{z}$ večanjem brezposelnosti najbolj prizadeva prav gospodarsko manj razvito severovzhodno Slovenijo. Zato lahko, $v$ kolikor ne bomo dovolj pozorni, ta proces najbolj prizadane že danes gospodarsko zelo zaostala in demografsko ogrožena ter periferna obmejna območja. Geografi moramo opozoriti tudi na dejstvo, da manjšanje števila zaposlenih $\mathrm{v}$ industriji in večanje števila brezposelnih, med katere so vključeni številni dnevni migranti iz perifernih območij, lahko, v kolikor ne bomo snovali regionalnega razvoja na drobnem in preko meje povezanem gospodarstvu, pripelje do popolne razselitve obmejnih območij.

\section{LITERATURA}

Gallusser W., 1981, Grenze und Kulturlandschaft. Regio Basiliensis XXII/ 2+3, Basel, s. $59-68$.

Klemenčič V., 1978, Grenzregionen und nationale Minderheiten. Socialno-geografski problemi obmestnih in obmejnih območij. Geographica Slovenica 8, Ljubljana, s. $7-20$.

Malchus Fr. V., Grenzueberschreitende Zusammenarbeit europaeischer Grenzregionen. Der europaeische Gemeindetag No.4.

Europaeisches Symposium der Grenzregionen, Die Zusammenarbeit europaeischer Grenzgebiete, Vorlaeufiger Basisbericht ausgearbeitet von Dr.Fr.V. Malchus, Teil II, Strasbourg, 1972.

Meier J., 1983, Grenzen und Raumforschung - eine Problemskizze, Staatsgrenzen und Einfluss auf Raumstrukturen und Verhaltensmuster (I. Teil - Grenzen in Europa). Bayreuth, s. 9 - 19.

Valussi G., 1976, La geografia di fronte alle esigenze dell' interdisciplinarita. Estratto de la geografia nelle scuole.

Klemenčič V., 1984, Geographische Probleme der Grenzraeume Sloweniens.Oesterreich in Geschichte und Literatur mit Geographie, Wien, Heft 6, s. 387 - 400.

Gosar A., Klemenčič V., Kočevar R., Pak M., Žagar M., 1978, Einfluss des Tourismus auf die Wandlung der Grenzregionen in Slowenien. Tourism and Borders Proceedings of the Meeting of the IGU Work Group, Ljubljana/Trieste, s. 13 - 61.

Klemenčič V., 1976, The open Border and Border Regions as a new regional-geographic phenomen. Regionalnaja geografija, Moskva, s. 146 - 149.

Klemenčič V., 1981, Die Kulturlandschaft im nordwestlichen Grenzgebiet Jugoslawiens (SR Slowenien). Regio Basiliensis XXII/2+3, Basel.

Klemenčič V., 1973, Zum Raumrelevanz der Grundfunktion in Wirtschaftsgeographischen Strukturmuster Sloweniens. Muenchner Studien zur Sozial- und Wirtschaftsgeographie No. 7, Soavtor: K. Ruppert. 
Vrišer I., 1976, Industrialisierung von Slowenien. Sozialgeographische Fragestellungen, Frankfurt am Main, s. 183 - 194.

Moritsch A., 1969, Das nahe Triester Hinterland. Zum Wirtschaftlichen und sozialen Entwicklung von Beginn des 19. Jahrhunderts bis zum Gegenwart, Wien-KoelnGraz.

Klemenčič V., 1973, Topical problems of open boundaries - the case of Slovenia. Confini e regioni. Trieste, 1973, s. 123 - 133. soavtor: Jeršič Matjaž.

Olas L., 1976, Dvolastništvo - dejavnik razvoja v Prekmurju kot obmejni regiji. Geografski vestnik XLVII, Ljubljana, s. 151 - 155.

Olas L., 1978, Nekateri populacijski problemi Prekmurja kot obmejne regije. II. slovenskoslovaški geografski simpozij, Maribor, s. 163 - 169.

Pak M., 1978, Meja kot faktor razvoja obmejnih območij. Zbornik radova sa naučnog simpozijuma geografski problemi pograničnih regija naše zemlje, Vranje, s. 13 23.

Klemenčič V., 1987, Državna meja na območju SR Slovenije in obmejna območja kot nov geografski fenomen. Razprave in gradivo 20. Ljubljana, 1987, s. 59 - 77.

The Geography of Border Landscapes. London and New York, 1991.

Minghi J.V., 1991, From conflict to harmony in border landscapes. The Geography of Border Landscapes. London and New York, s. 15 - 31.

Gallusser W.A., 1991, Geographical investigations in boundary areas of the Basle regio ("Regio"). The Geography of Border Landscapes. London and New York, s. 31 $-43$.

Klemenčič V., Bufon M., 1991, Geographic problems of frontier regions: The case of the Italo-Yugoslav border landscape. The Geography of Border Landscapes, London and New York, s. 86 - 104

Klemenčič V., 1990, Koprsko kot obmejno, narodnostno mešano in terciarizirano območje. Primorje - Zbornik 15. zborovanja slovenskih geografov, Portorož, s. 99 - 107.

Europa - Neue Konturen eines Kontinents. Oldenburg, 1993.

Klemenčič V., 1993, National Minorities as an Element of the Demographic and Spatial Structure of Alpine - Adriatic - Pannonia Region. GeoJournal, Ljubljana 1993, s. $207-215$.

Bufon M., 1993, Cultural and Social Dimensions of Borderlands : The Case of the Italo Slovene Trans-border Area. GeoJournal, Ljubljana, 1993, s. 235 - 241.

Klemenčič V., Genorio R., 1993, The New State of Slovenia and its Function within the Frame of Europe. GeoJournal, Ljubljana, s. 323 - 335.

Černe A., 1993, The Transport System of Slovenia. GeoJournal, Ljubljana, s. 335 - 339. 


\section{DIE GEOPOLITISCHE LAGE SLOWENIENS SAMT THEORETISCHER UND METHODOLOGISCHER BEWERTUNG DER TYPEN VON GRENZREGIONEN}

\section{Zusammenfassung}

Aus der Sicht Europas is Slowenien ingesamt als eine Grenzregion zu betrachten. Die eigene regionale Entwicklung ist wegen der Naehe der slowenisch-italianischen, der slowenischoesterreichischen, der slowenisch-ungarischen und der slowenisch-croatischen Grenze fast in allen Bereichen der Wirtschaft und des altaeglischen Lebens von der geopolitischen Lage Sloweniens in Europa, beziehungsweise von der bedeutenden Verkehrwegeausrichtung die vier Grossraumeinheiten Europas verbinden und sich in Slowenien kreutzt und beeintraechtigt. Die geopolitische Situation der Raumstrukturen und Raumprozesse hatte sich durch historisch bedingte Entwicklungphasen dauernd geaendert womit die internationale Bedeutung und der Charakter Sloweniens beintraechtigt wurde. Dadurch ist auch die Function der Grenzregionen konstant veraendert worden, wobei deren Typ von der Gestaltung verchiedener Nachfolgestaaten auf dem Territorium des einst einheitlichen Koenigreichs Oesterreich-Ungarn abhaengig gewesen ist. In bestimmter Form sind Grenzregionen auch von der jahrhundertelangen Provinzgrenzziehung inerhalb OesterreichUngarns und Italiens abhaengig gewesen. Diesen geschichtlichen Rahmenbedingungen mussten sich Raumstrukturen und Raumfunktionen anpassen. Die regionale Gestaltung Sloweniens, samt Grenzregionen wurde von der Entwicklungpolitik des Vielvolkerstaates Jugoslavien bis 1991 beeintraechtigt. Die Raum- und Regionalplanung Sloweniens der letzten drei Jahrzehnte ist auf eine ausbalancierte Entwicklung der Regionen ausgerichtet gewesen. Darin inbegriffen ist auch das Prinzyp der gleichmaessigen raum-regionalen Entwicklung Sloweniens, die stuffenweise Oeffnung der Grenzen und die immer intensiver werdende Anbindung der slowenischen Wirtschaft an Grenzregionen in Italien und Oesterreich gewesen.

Die entwicklung einzelner Grenzregionen Sloweniens ist von der Stuffe der wirtschaftlichen Entwicklung angrenzender Staaten abhaengig gewesen. Einen hindernden Moment stellte die Grenzziehung an den Bergruecken der Julischen Alpen und den Karawanken dar. Trotzt offener Grenze kam hier zu keiner intensiveren Wirtschafts- und Kulturverbindung.

Bei der Bewertung grenzregionaler Typen duerfen Forscher die Bedeutung der Minderheiten im Grenzraum nicht uebersehen. Die Minderheiten sind oft die Ursache der Gestaltung engerer zwischenstaatlicher Beziehungen und die Grundbasis eines neuen, etnisch mischsprachigen Grenzgebiet-Typus deren Charakteristiken von Geographen schon im Verlauf einiger Abschnitte slowenischer Grenzen bewertet wurden. Besonders:

- entlang der slowenisch-italienischen Grenze im Gebiet von Koper, wo Italiener samt der Slowenen - Mehrheits-bevoelkerung vermischt im Grenzraum ansaessig sind, als auch entlang derselben Grenze in Italien, wo die slowenische innerhalb italienischer Mehrheitsbevoelkerung verweilt; 
- entlang der slowenisch-oesterreichischen Grenze, wo Slowenen den Grenzraum gemeinsam mit Oesterreichern in Kaernten und in der Steiermark teilen; und

- entlang der slowenisch-ungarischnen Grenze, wo Slowenen den Raum entlang des RaabeFlusses in Ungarn samt Magyaren besiedeln, und die ungarische Minderheit im Uebermurgebiet in Slowenien mit Slowenen den Grenzraum teilt. 